\title{
Inguinal Herniation of Urinary Bladder
}

\author{
${ }^{1}$ Siddharth P Dubhashi, ${ }^{2}$ Ratnesh Jenaw
}

\begin{abstract}
Urinary bladder hernia is evident into 1 to $3 \%$ of inguinal hernias. About $7 \%$ of bladder hernias are diagnosed preoperatively. The herniation of the bladder occurs in an acquired direct inguinal hernia with the bladder setting into the hernia along with the peritoneal sheath. This is a report of an elderly male with a para-peritoneal vesical hernia. This is a rare condition requiring a high index of suspicion to prevent complications like urinary tract infection, obstruction and incarceration of bladder wall.
\end{abstract}

Keywords: Elderly males, Inguinal, Para-peritoneal, Urinary complaints, Vesical hernia.

How to cite this article: Dubhashi SP, Jenaw R. Inguinal Herniation of Urinary Bladder. J Mahatma Gandhi Univ Med Sci Tech 2016;1(2):66-67.

\section{Source of support: Nil}

Conflict of interest: None

\section{INTRODUCTION}

Vesical hernias were described in 14th century by French Surgeon Guy de Chauliac. ${ }^{1}$ Urinary bladder hernia is evident in 1 to $3 \%$ of inguinal hernias. They are frequently unilateral on the right side with $70 \%$ male predominance. ${ }^{2}$ About $7 \%$ of bladder hernias are diagnosed preoperatively. ${ }^{3}$

\section{CASE REPORT}

This is a case of a 70 years old male presenting with a right-sided recurrent inguinal hernia, with complaints of difficulty in micturition since 3 years. On examination, it was a $5 \times 4 \mathrm{~cm}$ firm swelling, without expansile cough impulse. There was no evidence of significant prostatomegaly, clinically and radiologically. On exploration, there was evidence of herniation of bladder

${ }^{1}$ Director, Professor and Head ${ }^{2}$ Postgraduate Student
${ }^{1}$ Academics and Student Affairs; Department of Surgery, Mahatma
Gandhi Medical College and Hospital, Jaipur, Rajasthan, India
${ }^{2}$ Department of Surgery, Mahatma Gandhi Medical College and
Hospital, Jaipur, Rajasthan, India

Corresponding Author: Siddharth P Dubhashi, A2/103 Shivranjan Towers, Someshwarwadi, Pashan, Pune, Maharashtra, India, Phone: +91-9881624422, Fax: 020-25883666, e-mail: spdubhashi@gmail.com

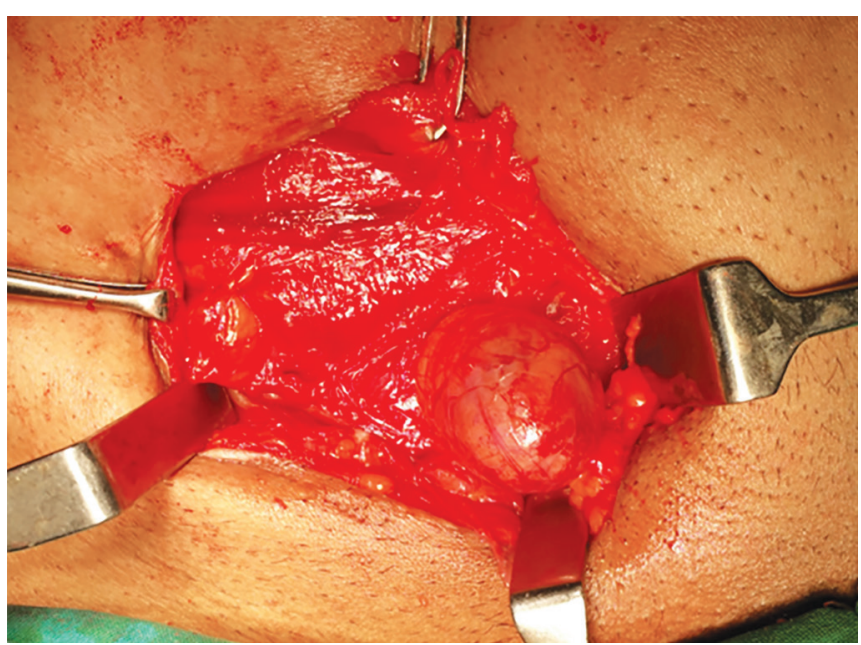

Fig. 1: Inguinal herniation of urinary bladder

extraperitoneally along the hernia sac (paraperitoneal) (Fig. 1). The bladder was reduced inside and defect closed with nonabsorbable sutures. The postoperative period was uneventful.

\section{DISCUSSION}

The herniation of the bladder occurs in an acquired direct inguinal hernia with the bladder setting into the hernia along with the peritoneal sheath. ${ }^{4}$ Various factors contributing to inguinal herniation of urinary bladder include: Old age, bladder outlet obstruction, loss of bladder tone with weakening of supporting structures, obesity, pericystitis, and pelvic masses. ${ }^{5,6}$ These are classified as extraperitoneal (30\%), paraperitoneal (60\%) and totally intraperitoneal (10\%). ${ }^{7}$ They remain asymptomatic usually presenting with urinary complaints and are diagnosed intraoperatively. Classical history suggests reduction of size of hernia after urination and ability to pass urine after pressure on hernia sac. ${ }^{6}$ The relative position of the bladder to the peritoneum is of crucial value, since the peritoneal tissue can obscure an adjacent bladder wall causing an unintentional injury during operative procedures. ${ }^{8}$ Ultrasound is an effective diagnostic imaging modality. Computed tomography scans can also accurately demonstrate vesical hernias. ${ }^{1}$ Patients are managed with standard inguinal hernia repair with or without mesh. ${ }^{9}$ Bladder resection is required only in case of necrosis or diverticulum. ${ }^{10}$ 


\section{CONCLUSION}

Urinary bladder inguinal hernia is a rare condition requiring a high index of suspicion to prevent complications like urinary tract infection, obstruction and incarceration of bladder wall. Ultrasonography is a valuable imaging modality for preoperative diagnosis.

\section{REFERENCES}

1. Server Pastor G, Lopez Cubillana P, Hita Villaplana G, Prieto Gonzalez A, Hita Rosino E , Server Falgas G. Inguinal bladder hernia: Report of 4 cases. Actas Urol Esp 1994;18:670-673.

2. Andac N, Baltacioglu N, Tuney $\mathrm{D}$, et al. Inguinoscrotal bladder herniation: is $\mathrm{CT}$ a useful tool in diagnosis? Clinical Imaging 2002;26(5):347-348.

3. Kishore Kumar BN, Sakalecha AK, Das D , Kumar PB. Urinary bladder herniation-rare preoperative incidental finding radiological features. Int J Biol Med Res 2012;3(1):1459-1460.
4. Deshmukh A, Jadhav A, Pawar S. Diagnosis of inguinal bladder hernias: current role of sonography. Int J Scientific Study 2015;3(1):216-218.

5. Gurer A, Ozdogan M, Ozlem N, Yildirim A, Kulacoglu H, Aydin R. Uncommon content in groin hernia sac. Hernia 2006;10(2):152-155.

6. Bacigalupo LE, Bertolotto $\mathrm{M}$, Barbiera $\mathrm{F}$, et al. Imaging of urinary bladder hernias. Am J Roentgenol 2005;184:546-551.

7. Ojea Calvo A, Rodriguez Alonso A, Perez Garcia D, Dominguez Freire F, Alonso Rodrigo A, Rodriguez Iglesias B, et al. A massive hernia of the bladder into the scrotum: a report of a case. Actas Urol Esp 1999;23:79-82.

8. Karaman ZC, Saray A, Dorak C, Tamac NI. Ultrasonographic diagnosis of massive bladder hernia. J Clin Ultrasound 1993;21:534-536.

9. Wagner AA, Arcand P, Bamberger MH. Acute renal failure resulting from huge inguinal bladder hernia. Urology 2004; 64:156-157.

10. Epner SL, Rozenblit A, Gentile R. Direct Inguinal hernia containing bladder carcinoma: CT demonstration. AJR 1993; 161:97-98 